\title{
Light-addressable electrochemical sensing of dopamine using on n-silicon/gold Schottky junctions
}

Irina M. Terrero Rodríguez, ${ }^{\dagger}$ Alexandra J. Borrill, ${ }^{\ddagger}$ and Glen D. O’Neil ${ }^{\dagger *}$

${ }^{\dagger}$ Department of Chemistry and Biochemistry, Montclair State University, Montclair, NJ 07043, United States

Department of Chemistry and the Centre for Doctoral Training in Diamond Science and Technology, University of Warwick, Coventry, CV4 7AL, United Kingdom

*To whom correspondence should be addressed: oneilg@montclair.edu

Here, we report the use of semiconductor/metal (Schottky) junctions as light-addressable electrochemical sensors (LAES). We employ an $\mathrm{n}-\mathrm{Si} / \mathrm{Au}$ Schottky junction prepared by electrodeposition of $\mathrm{Au}$ nanoparticles (NPs) on a freshly etched n-Si photoelectrode. The Au layer establishes the light-addressable voltage range where the semiconductor is in depletion, acts as the electrochemically active sensing surface, and serves to protect the photoelectrode from anodic corrosion in an aqueous environment. We characterized the LAES using scanning electron microscopy, electrochemical impedance spectroscopy, and cyclic voltammetry. The sensors demonstrate near reversible electrochemical behavior for the oxidation of ferrocene methanol and potassium ferrocyanide. Moreover, n-Si/Au LAES were stable for 1000 cyclic voltammetry cycles in an aqueous electrolyte - even though the n-Si surface was only partially covered with Au NPs. We also challenged the LAES to detect the neurotransmitter dopamine and found that the sensors were quantitative over the range from $15-500 \mu \mathrm{M}$ in buffer with a limit of detection of 8.4 $\mu \mathrm{M}$, demonstrating that these sensors have potential for quantifying freely-diffusing neurotransmitters. Additionally, we used local illumination to generate a virtual array of electrochemical sensors for dopamine as a strategy for circumventing sensor fouling. When the total area of the sensor was illuminated, the dopamine signal rapidly decayed due to formation of polydopamine on the surface of the electrode, rendering the sensor useless. By locally illuminating a small portion of the photoelectrode, many measurements of fouling analytes can be made on a single sensor with a single electrical connection by moving the light beam to a fresh area of the sensor. Taken together, these results pave the way for Schottky junction light-addressable electrochemical sensors to be useful for a number of interesting future applications in chemical and biological sensing. 


\section{INTRODUCTION}

Light-addressable electrochemical sensing (LAES) is a technique which uses light to trigger a spatially and temporally selective electrochemical reaction on the surface of a semiconducting photoelectrode. ${ }^{1,2}$ The basic operating principle of LAES using an n-type semiconductor and a high-work function metal is shown in Scheme 1a. Here, an n-type Si photoanode is coated in a layer of Au and placed in a solution of a reduced redox species, R. In the dark regions of the electrode under an appropriate applied potential, the oxidation of $\mathrm{R}$ to $\mathrm{O}$ is not possible because the semiconductor is in depletion. When a semiconductor is depletion, the concentration of minority charge carriers (i.e., holes for n-type materials or electrons for p-type materials) is insufficient to enable redox reactions at the sensor-solution interface. ${ }^{3-8}$ For n-type semiconductors, a LAES will be in depletion at potentials more positive that the flat-band potential, $E_{\mathrm{fb}}$. For p-type semiconductors, depletion conditions are met when the electrode is biased at potentials more negative than $E_{\mathrm{fb}}$. In the areas that are illuminated, $\mathrm{R}$ is able to oxidize to form the product O because electron-hole pairs generated in the semiconducting layer are separated and transported to the interfaces - holes are transported to the sensing interface while the electrons are transferred to the Ohmic connection. ${ }^{9}$ LAES has led to new applications in electrochemical sensing, ${ }^{10}$ imaging, ${ }^{11-13}$ surface patterning, ${ }^{14,15}$ and even fundamental studies of semiconductor photoelectrochemistry. ${ }^{16}$

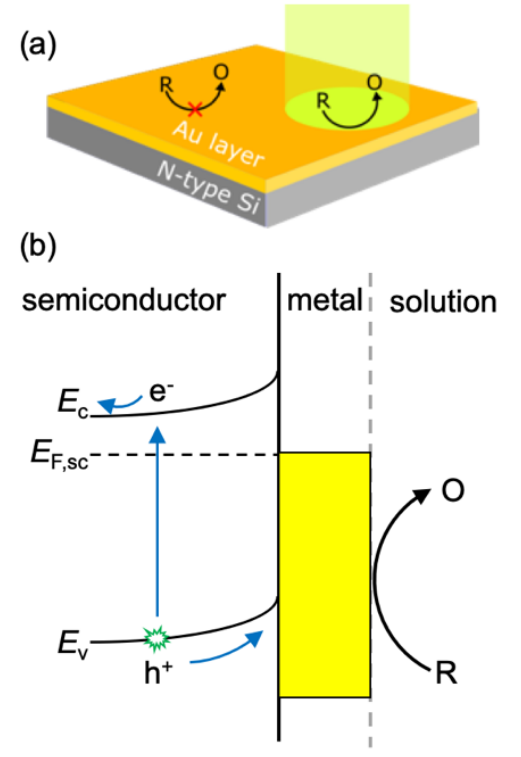




\section{Scheme 1}

In order to perform light-addressable electrochemical sensing, three important barriers must be overcome. The first major barrier for LAES is that many semiconductor surfaces are unstable and prone to anodic corrosion in aqueous solution. ${ }^{17}$ In fact, the early studies that characterized electron transfer across the Si-solution interface required dry, non-aqueous solvents and many were performed in inert atmospheres. ${ }^{18-20}$ A number of approaches have been developed to protect the interface including employing ultrathin oxides, ${ }^{21-24} 1$ - and 2D materials, ${ }^{25-27}$ wet-chemical functionalization, ${ }^{28}$ and continuous thin metal films. ${ }^{29-31}$ A second major barrier for LAES is that close electronic coupling between the $\mathrm{Si}$ surface and the redox couple is required for efficient electron transfer. One approach to accomplish this, popularized by Gooding and co-workers, is to covalently attach the redox species to the semiconductor, ${ }^{28}$ which is efficient but limits the number of possible redox couples by requiring appropriate linking chemistry and can only indirectly measure freely diffusing species. An alternative approach, which is widely used in water splitting applications, ${ }^{23}$ is to use high density of states metal films or NPs on the surface of the electrode. ${ }^{32}$ This approach is attractive because the LAES functions like a traditional metal electrode that can be turned on/off with light and can be used to directly measure freely diffusing redox couples. The third challenge is to control the energetics of the semiconductor interface that enable LAES. For LAES, the semiconductor must be in depletion and the redox potential must be more positive (on the electrochemical scale) than the conduction band edge. ${ }^{2}$ For a semiconductor/metal junction, light-activated electrochemistry will occur for semiconductor-metal combinations with a sufficient barrier height, which is the difference between the semiconductor's Fermi level and the work function of the metal.

The vast majority of recent LAES studies to date use a Si electrode modified with a monolayer of 1,8-nonadiyne that protects the Si interface and provides a route for functionalizing the electrode with redox couples $^{10-12,33-37}$ or NPs. ${ }^{32,38}$ This Si modification scheme has excellent electrochemical performance, stability, and versatility. The first report from Gooding's group showed ideal electrochemical behavior for surface-bound ferrocene and anthraquinone redox couples, ${ }^{10}$ and the sensing surface has been subsequently used for DNA sensing, ${ }^{10}$ live cell $\mathrm{K}^{+}$imaging, ${ }^{11}$ selective cell capture and release, ${ }^{37}$ in addition to probing 
the fundamentals of charge transfer at the semiconductor-liquid interface. ${ }^{16}$ One challenge of this approach is that the samples require complex, multi-step syntheses to modify the Si surface. In addition, measurement of freely diffusing redox species requires additional modifications. ${ }^{32,38}$ Other viable approaches employ transition metal oxides ${ }^{39}$ or quantum $\operatorname{dots}^{40,41}$ as the semiconductor layer. Transition metal oxides are attractive because they do not corrode in aqueous solutions at anodic potentials, however they typically have poor electrochemical performance compared to Si.

Here, we demonstrate that Schottky junctions formed from n-type Si and Au can be used as LAES for dopamine. We fabricated LAES by a one-step electrodeposition of Au NPs directly on a freshly-etched n-type Si (100) photoanode. $^{30,31}$ We imaged the surfaces using scanning electron microscopy (SEM) and investigated the electrochemical behavior of the sensors using cyclic voltammetry (CV) using outer- and inner-sphere redox couples. The $\mathrm{n}-\mathrm{Si} / \mathrm{Au}$ samples were stable under illumination for $1000 \mathrm{CV}$ cycles (approx. time $\approx 3$ hours), even though the electrodes are only partially covered with Au NP. The sensors were used to detect dopamine at low- $\mu \mathrm{M}$ concentrations. Unfortunately, we found that the dopamine fouled the sensor surface during repeated cycling, with which is a significant problem for electrochemical dopamine sensors. ${ }^{42,43}$ To circumvent this issue, we use a virtual array format, where a small portion of the LAES is activated by local illumination with a focused light beam. The virtual array format is advantageous because once dopamine fouls a small portion of the sensor, a new sensor can be activated by moving the focused light beam to a new location. This approach has the advantages of an individually addressable electrode array, but without the complex hardware or fabrication requirements. These sensors greatly simplify the preparation of current LAES and expand the scope of potential applications for LAES by enabling benchtop fabrication using inexpensive and commercially available materials.

\section{EXPERIMENTAL}

Materials and Solutions. Potassium chloride $(\mathrm{KCl})$, sodium chloride $(\mathrm{NaCl})$, disodium phosphate $\left(\mathrm{Na}_{2} \mathrm{HPO}_{4}\right)$, monosodium phosphate $\left(\mathrm{NaH}_{2} \mathrm{PO}_{4}\right)$, and potassium ferrocyanide $\left(\mathrm{K}_{4}\left[\mathrm{Fe}(\mathrm{CN})_{6}\right]\right)$ were from Fisher Scientific and were certified ACS grade. Ferrocene methanol (FcMeOH; 97\%) was from Acros 
Organics. Hydrogen tetrachloroaurate(III) trihydrate $\left(\mathrm{HAuCl}_{4} \cdot \mathrm{H}_{2} \mathrm{O} ; 99.99 \%\right)$ was from Alfa Aesar. Dopamine hydrochloride was from Sigma. All chemicals were used as received. Solutions containing FcMeOH were sonicated for 60 minutes and passed through a $0.2 \mu \mathrm{m}$ polycarbonate filter before use. All solutions were prepared using 18.2 M $\Omega \bullet \mathrm{cm}$ water (Millipore Simplicity).

Electrode preparation. The LAES used in this study were prepared using n-type Si (100) and highly doped (metallic) p*-Si (100) from Pure Wafer (San Jose, CA). Both wafers were single-side polished and 500-550 $\mu \mathrm{m}$ thick. The n-type wafers were doped with phosphorous (resistivity $1-5 \Omega \bullet \mathrm{cm}$ ) and the $\mathrm{p}^{*}$ wafers were doped with boron (resistivity $<0.005 \Omega \bullet \mathrm{cm}$ ). Ohmic back contacts were prepared by scratching the unpolished side of the wafer with a diamond scribe to remove the native oxide and subsequently contacting a $\mathrm{Cu}$ wire using indium solder. The back contacts were insulated by sealing the entire assembly in 3M Electroplater's tape, which included a 4-mm opening that allowed exposure of the front Si surface to the electrolyte.

$\mathrm{Au}$ NPs were electrodeposited onto the polished front surface of Si in order to protect the underlying Si surface, to establish a rectifying semiconductor-metal junction, and to increase the electronic coupling between the semiconductor and redox species, using a modified procedure previously described by Allongue et al. ${ }^{30}$ Briefly, the electrode was etched in $40 \% \mathrm{NH}_{4} \mathrm{~F}$ solution (semiconductor grade) for 10 minutes at room temperature to remove the native oxide. The electrode was rinsed with copious amounts of DI water, and was immersed in the electrodeposition solution. The electrode was biased at $-1.9 \mathrm{~V}$ vs. $\mathrm{Ag} \mid \mathrm{AgCl}$ before being dipped in the deposition solution to prevent the formation of $\mathrm{SiO}_{\mathrm{x}}$ during exposure to the electrolyte. The deposition solution consists of $0.1 \mathrm{mM} \mathrm{HAuCl}_{4}, 1 \mathrm{mM} \mathrm{KCl}, 0.1 \mathrm{M} \mathrm{K}_{2} \mathrm{SO}_{4}$ and $1 \mathrm{mM}$ $\mathrm{H}_{2} \mathrm{SO}_{4}$. The deposition was carried out with room lights on, but without direct illumination of the semiconductor surface. Four different deposition times $(5,10,15$, and 20 mins) were tested in order to determine if there was a measurable impact on the observed voltammetry.

Electrochemical measurements. Bulk electrochemical experiments were carried out using a $\mathrm{CH}$ Instruments $660 \mathrm{C}$ potentiostat or $760 \mathrm{E}$ bipotentiostat. All electrochemical measurements were carried out 
in a $100-\mathrm{mL}$ flat-walled glass electrochemical cell using a three-electrode arrangement. $\mathrm{A} \mathrm{Ag} / \mathrm{AgCl}$ electrode served as the reference and a graphite rod or Pt wire as the counter. Au disk electrodes (2 mm diameter) were obtained from CH Instruments (USA). Electrochemical impedance spectra (EIS) for MottSchottky measurements were carried out in the dark at 35, 42.5, 50 and $65 \mathrm{kHz}$ in an electrolyte containing $1 \mathrm{mM} \mathrm{FcMeOH} / 0.1 \mathrm{M} \mathrm{KCl}$ over an appropriate potential range, typically -0.8 to $0 \mathrm{~V}$ vs. Ag|AgCl. A separate impedance measurement was made every $20 \mathrm{mV}$. The space charge capacitance $\left(C_{\mathrm{sc}}\right)$ was calculated from the impedance data using the following equation:

$$
Z^{\prime \prime}=\frac{1}{2 \pi v C_{s c}}
$$

where Z" is the imaginary component of the impedance, and $v$ is the frequency in Hz. Illumination of the semiconductor was provided using a white light LED (AM Scope) with a measured power density of 85 $\mathrm{mW} \mathrm{cm}$. Virtual array experiments were performed using a HEKA ELP 1 scanning electrochemical workstation equipped with a PG 160 USB bipotentiostat and a 530-nm LED coupled to a fiber optic cable, a F240SMA-532 collimator and an 10x objective (see Section S6 in the supporting information for more details). The measured power density was $\sim 200 \mathrm{~mW} \mathrm{~cm}^{-2}$. Dark measurements were performed using a home-built dark box to eliminate ambient room light.

Physical Characterization. Optical microscopy was performed using an AmScope MR400 metallurgical microscope using a 10x objective to check the macroscale homogeneity of the Au surface. Field emission scanning electron microscopy (FE-SEM) was performed using a Zeiss GeminiSEM 500 on InLens mode operating at $15 \mathrm{kV}$. Energy-dispersive X-ray spectroscopy (EDX) was performed using a Hitachi S-3400N SEM in secondary electron mode using a 30-kV accelerator voltage.

\section{RESULTS AND DISCUSSION}

Surface characterization. We prepared n-Si/Au Schottky junctions by electrodepositing Au on a freshly etched n-type $\mathrm{Si}(100)$ electrode using an electrolyte containing $0.1 \mathrm{mM} \mathrm{HAuCl}_{4}, 1 \mathrm{mM} \mathrm{KCl,} 0.1$ $\mathrm{M} \mathrm{K}_{2} \mathrm{SO}_{4}$ and $1 \mathrm{mM} \mathrm{H}_{2} \mathrm{SO}_{4}$, as previously described by Allongue et al. ${ }^{30}$ Figure 1 shows an FE-SEM image of $\mathrm{Au}$ NPs grown on $\mathrm{n}-\mathrm{Si}$ for 5 minutes at $-1.9 \mathrm{~V}$ vs. $\mathrm{Ag} / \mathrm{AgCl}$. Under the electrodeposition conditions, the 
n-Si surface is partially covered with Au NPs. Statistical analysis of the NPs performed using ImageJ shows that the NPs are $15 \pm 6 \mathrm{~nm}$, cover approximately $31 \%$ of the surface, and the density of particles on the surface is approximately $1.6( \pm 0.2) \cdot 10^{11} \mathrm{~cm}^{-2}$. EDX analysis confirms that the NPs formed on the surface are Au (Fig. S1). These results are similar to those reported by Switzer et al., who deposited continuous epitaxial Au films on n-Si (111) using a similar procedure. ${ }^{31}$ However, the films grown on n-Si (111) had coalesced after a five five-minute deposition. The differences may be due to the crystal orientation of the substrates used in each study ((100) vs. (111)).

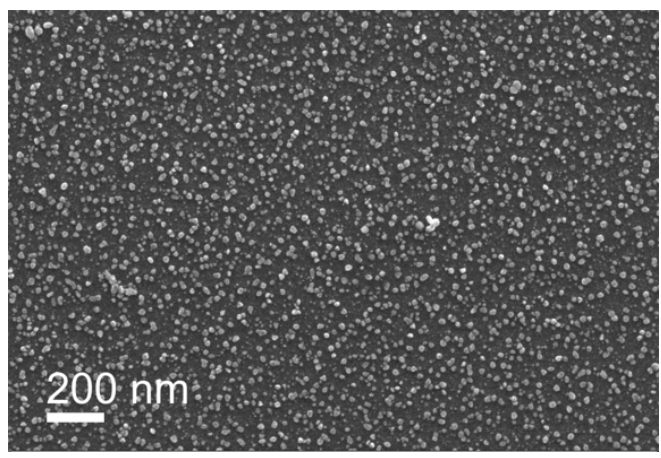

Figure 1: FE-SEM images of n-Si photoanodes prepared by electrodepositing Au NPs for 5 minutes at $1.9 \mathrm{~V}$ vs. $\mathrm{Ag} / \mathrm{AgCl}$.

n-Si/Au Schottky junction energetics. We characterized the energetics of the n-Si/Au Schottky junction to determine the potential range over which the sensor would be light-addressable by measuring the flat band potential $\left(E_{\mathrm{fb}}\right)$ and the conduction and valence band edges. ${ }^{44} E_{\mathrm{fb}}$ is the potential where there is no band bending in the semiconductor and is useful for estimating the approximate voltage range over will be in depletion (and therefore photoactive). Figure 2a shows impedance data (presented as a Mott-Schottky plot) for a five-minute $\mathrm{n}-\mathrm{Si} / \mathrm{Au}$ sensor in an electrolyte containing $1 \mathrm{mM} \mathrm{FcMeOH}$ and $0.1 \mathrm{M} \mathrm{KCl}$ recorded at $35 \mathrm{kHz}$. Figure $\mathrm{S} 2$ in the supporting information shows similar plots collected at $42.5,50$ and $65 \mathrm{kHz}$. The flat band potential of the $\mathrm{n}-\mathrm{Si} / \mathrm{Au}$ interface was determined from the x-intercept of the Mott-Schottky plot to be $-0.66 \pm 0.02 \mathrm{~V}$ vs. $\mathrm{Ag} / \mathrm{AgCl}$ (average of four frequencies \pm one standard deviation). Using $E_{\mathrm{fb}}$, we estimated the conduction band edge position $\left(E_{\mathrm{cb}}\right)$ to be $-0.93 \pm 0.03 \mathrm{~V}$, using equation $2::^{45}$

$$
E_{c b}=E_{f b}+k_{B} T \ln \left(\frac{N_{d}}{N_{c}}\right)
$$


where $k_{\mathrm{B}}$ is Boltzmann's constant, $N_{\mathrm{d}}$ is the bulk dopant concentration $\left(=(7.6 \pm 0.3) \cdot 10^{14} \mathrm{~cm}^{-3}\right.$, obtained from the slope of the Mott-Schottky plot), ${ }^{44}$ and $N_{\mathrm{c}}$ is the effective density of states for the conduction band $\left(=2.8 \cdot 10^{19} \mathrm{~cm}^{-3}\right.$ for $\left.\mathrm{Si}\right)$. We estimated the valence band edge to be $0.17 \mathrm{~V}$ vs. $\mathrm{Ag} / \mathrm{AgCl}$ using the conduction band edge and the Si band gap $(1.1 \mathrm{eV})$. Details of the calculations can be found in the supporting information, section S2. Taken together, these sensors should be light-addressable when biased at potentials more positive than $-0.66 \mathrm{~V}$ vs. $\mathrm{Ag} / \mathrm{AgCl}$.
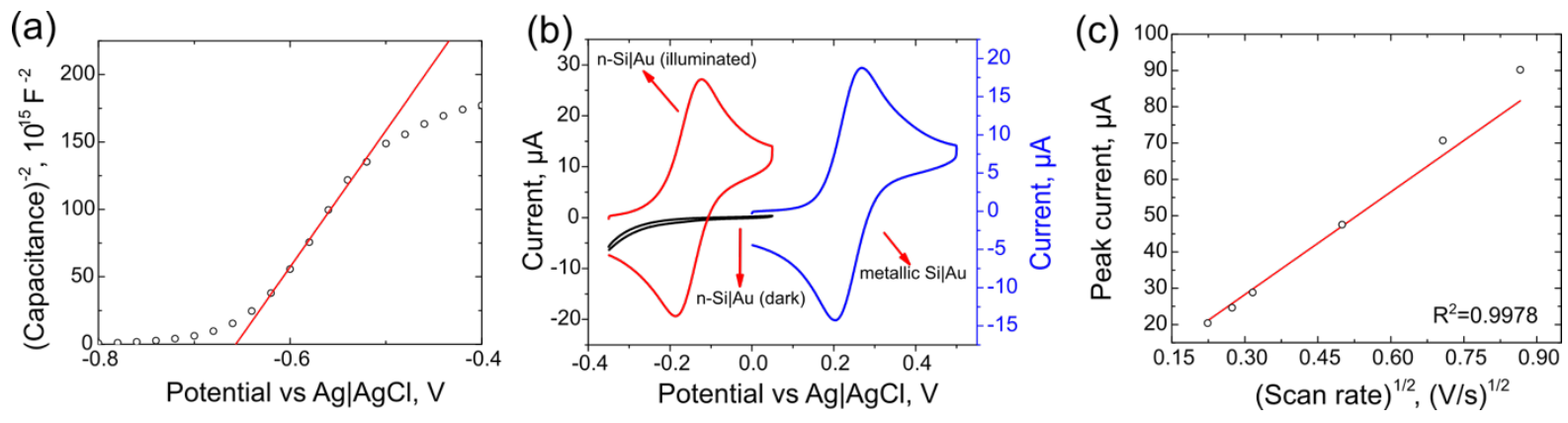

Figure 2: Electrochemical characterization of n-Si/Au Schottky junction sensors. (a) Mott-Schottky plot of n-type $\mathrm{Si} / \mathrm{Au}$ electrode at $35 \mathrm{kHz}$; (b) CVs of $1 \mathrm{mM} \mathrm{FcMeOH}$ using highly-doped p*-Si/Au electrodes in the dark (blue trace), semiconducting $\mathrm{n}-\mathrm{Si} / \mathrm{Au}$ photoelectrodes in the dark (black trace) and fully illuminated semiconducting n-Si/Au photoelectrodes (red trace). Scan rate $=0.1 \mathrm{~V} \mathrm{~s}^{-1}$. (c) Randles-Sevcik analysis of anodic peak current versus square root of scan rate confirming that diffusion of the reactant is limiting the current response. Dots represent the experimental data, while the solid line represents the theoretical values.

Electrochemical characterization of $n$-Si/Au Schottky junctions. We first characterized the photoelectrochemical behavior of the $\mathrm{n}-\mathrm{Si} / \mathrm{Au}$ Schottky junctions using $\mathrm{CV}$ in $\mathrm{FcMeOH}$. FcMeOH is an outer-sphere redox couple known to have very fast heterogeneous electron transfer (HET) kinetics. ${ }^{46}$ Figure $2 \mathrm{~b}$ shows $\mathrm{CVs}$ of $1 \mathrm{mM} \mathrm{FcMeOH}$ using $\mathrm{n}-\mathrm{Si} / \mathrm{Au}$ and $\mathrm{p}^{*}-\mathrm{Si} / \mathrm{Au}$ control samples in the presence and absence of $85 \mathrm{~mW} \mathrm{~cm}^{-2}$ illumination. First, consider the blue trace in Fig. $2 \mathrm{~b}$ which shows a $\mathrm{CV}$ for the oxidation of $\mathrm{FcMeOH}$ using a highly-doped (metallic) $\mathrm{p}^{*}-\mathrm{Si} / \mathrm{Au}$ substrate in the dark. As expected, the electrochemical behavior of this sample is excellent, as demonstrated by the separation of the peak potentials $\left(\Delta E_{\mathrm{p}}=65 \pm 2 \mathrm{mV}\right.$ at $0.1 \mathrm{~V} \mathrm{~s}^{-1}$; not corrected for $i R$ drop). This demonstrates that the electrodeposition of Au NPs on the surface of Si enables efficient electron transfer across the solid/liquid interface. The black trace in Fig. $2 \mathrm{~b}$ shows the semiconducting $\mathrm{n}-\mathrm{Si} / \mathrm{Au}$ photoelectrode in the absence of 
light. As expected from the Mott-Schottky measurements (Fig. 2a), the semiconducting n-Si/Au photoelectrode is inactive in the dark (Fig. 2b, black trace) because over this potential range the semiconductor is in depletion. Illuminating the entire surface using $85 \mathrm{~mW} \mathrm{~cm}^{-2}$ white light generates electron/hole pairs in the semiconductor which are transported to the Au NPs. Under illumination, the n$\mathrm{Si} / \mathrm{Au}$ sample becomes electrochemically active (Fig. 2b, red trace). By comparing the black trace to the red trace, the power of this technique is clearly demonstrated because the "turn on" electrochemical signal shows $\approx 100 \mathrm{x}$ greater signal upon the addition of light. The photooxidation occurs at a less positive potential than the required at a metallic electrode because the energy provided by the light shifts the electrode potential to more positive potentials and helps drive the redox process. ${ }^{2}$ We observe that this voltage shift differs slightly from electrode to electrode, but is typically $\sim 0.4 \mathrm{~V}$ more cathodic than $E^{\mathrm{o}}$. We varied the electrodeposition time $(5,10,15$, and 20 mins), but observed very little effect on the observed photovoltage shift or the CV peak separation, as shown in Fig. S3, and for all future studies we employed the five-minute deposition time. As a control experiment, we also performed $\mathrm{CV}$ of FcMeOH using a freshly-etched n-Si electrode without Au NPs (Fig. S4). Without Au NPs, the electrochemistry is very sluggish suggesting that the HET across the sensor/solution interface likely takes place on the Au particles, rather than the exposed Si.

We also characterized the n-Si/Au electrodes using $\mathrm{Fe}(\mathrm{CN})_{6}{ }^{4-}$ to determine if the light-addressable response was limited to $\mathrm{FcMeOH}$. Fig. S5 shows cyclic voltammograms of $\mathrm{Fe}(\mathrm{CN})_{6}{ }^{4-}$ in $0.1 \mathrm{M} \mathrm{KCl}$ using n-Si/Au and $\mathrm{Au}$ disk electrodes. The $E^{\mathrm{o}}$ for $\mathrm{Fe}(\mathrm{CN})_{6}{ }^{4-}$ is $\sim 0.25 \mathrm{~V}$ vs. $\mathrm{Ag} / \mathrm{AgCl}$ and it should therefore be light-activated using this sensor because $E^{\mathrm{o}}$ is more positive than $E_{\mathrm{fb}}$. The blue trace in Fig. S5 shows a CV of a metallic Au disk electrode. The black trace shows the n-Si/Au sensor in the dark and the red trace is the $\mathrm{n}-\mathrm{Si} / \mathrm{Au}$ under illumination. Comparison of the red and black traces demonstrate that the LAES is activated by light for the oxidation of $\mathrm{Fe}(\mathrm{CN})_{6}{ }^{4-}$. By comparing the red and blue traces, it is clear that the n-Si/Au sensor behaves nearly identically to the metallic Au disk. 
In order to characterize the mass-transport behavior of the n-Si/Au junctions, we performed $\mathrm{CV}$ over a range of scan rates $\left(0.05-0.75 \mathrm{~V} \mathrm{~s}^{-1}\right)$. Figure $2 \mathrm{c}$ shows a Randles plot of peak current versus the square root of scan rate $\left(v^{1 / 2}\right)$. The relationship between peak current and $\left(v^{1 / 2}\right)$ is linear $\left(R^{2}=0.9978\right)$ and indicates that diffusion of $\mathrm{FcMeOH}$ to the $\mathrm{n}-\mathrm{Si} / \mathrm{Au}$ Schottky junction is linear, caused by overlapping diffusion fields at each Au NP. ${ }^{47}$ This is expected given the high density and close spacing of the Au NPs. The expected gradient of the line was calculated using Eq. 3:

$$
i_{p}=268,600 n^{3 / 2} A D^{1 / 2} c_{b} v^{1 / 2}
$$

where $i_{\mathrm{p}}$ is the peak current, $n$ is the number of electrons transferred in the reaction $(=1), A$ is the electrode area $\left(=\pi r^{2} ; r=0.20 \pm 0.01 \mathrm{~cm}\right), D$ is the diffusion coefficient of the redox species $\left(\mathrm{cm}^{2} \mathrm{~s}^{-1} ; 7.8 \cdot 10^{-6} \mathrm{~cm}^{2} \mathrm{~s}^{-}\right.$ $\left.{ }^{1}\right),{ }^{48} \mathrm{Cb}_{\mathrm{b}}$ is the bulk concentration of the redox species $\left(=1 \bullet 10^{-6} \mathrm{~mol} \mathrm{~cm}{ }^{-3}\right)$, and $v$ is the scan rate $\left(\mathrm{V} \mathrm{s}^{-1}\right)$. The gradient from the experimental data $\left(=100 \pm 2 \mu \mathrm{As}^{1 / 2} \mathrm{~V}^{-1 / 2}\right)$ agrees reasonably well with the value predicted using equation $3\left(=94 \mu \mathrm{A} \mathrm{s}^{1 / 2} \mathrm{~V}^{-1 / 2}\right)$.

Numerous models have been developed to describe the kinetic behavior of semiconducting photoelectrodes, which are considerably more complex than metallic electrodes. ${ }^{49} \mathrm{With}$ metallic electrodes, the HET rate is not typically affected by charge transport in the metal. However, with semiconductors charge transfer, recombination, diode quality, and interfacial properties can all impact the overall rate. Based on the shape of the CVs in Fig. 2b and the close agreement with the Randles-Sevcik equation, we hypothesized that the HET rate constant, $k^{0}$, could be measured using the Nicolson method, where the peakto-peak separation in a $\mathrm{CV}$ is related the dimensionless parameter, $\psi \cdot \cdot^{50,51}$ This assumption would only account for HET across the metal/solution interface. Under most conditions, where the electron transfer kinetics are symmetrical $(\alpha \approx 0.5)$ and the diffusion coefficients of the oxidized and reduced species are equal, $\psi$ can be calculated by:

$$
\psi=k^{0} \sqrt{\frac{R T}{\pi F D}} v^{-0.5}
$$

where all of the variables have their usual meanings. The dimensionless parameter is calculated using an empirical relationship that depends on the peak-to-peak separation: ${ }^{52}$ 


$$
\psi=\frac{-0.6288+0.0021 n \Delta E_{p}}{1-0.017 n \Delta E_{p}}
$$

The HET rate constant for $\mathrm{FcMeOH}$ was determined to be $5.0( \pm 0.4) \cdot 10^{-2} \mathrm{~cm} \mathrm{~s}^{-1}$ and was calculated from the gradient of a plot of $\psi$ versus $v^{-1 / 2}$ (Fig. S6b). As a control experiment, we determined the HET rate constant to be $3.2( \pm 0.3) \cdot 10^{-2} \mathrm{~cm} \mathrm{~s}^{-1}$ using electrodes fabricated using metallic $\mathrm{p}^{*}$-Si/Au (Fig. S6e). Note the metallic $\mathrm{p}^{*}$-Si samples do not require generation and separation of carriers. The two $k^{0}$ values are similar, supporting our hypothesis that $k^{0}$ could be estimated by only considering electron transfer across the metal/solution interface.

Stability of n-Si/Au Schottky junctions. We studied the stability of the Au-coated Si photoelectrodes by performing $\mathrm{CV}$ for 1000 cycles at $0.1 \mathrm{~V} \mathrm{~s}^{-1}$ in aqueous $\mathrm{FcMeOH}$ solutions over $\approx 3$ hours. Fig. 3 shows the $1^{\text {st }}, 100^{\text {th }}, 200^{\text {th }}, 300^{\text {th }}, 400^{\text {th }}, 500^{\text {th }}, 600^{\text {th }}, 700^{\text {th }}, 800^{\text {th }}, 900^{\text {th }}$, and $1000^{\text {th }}$ cycles for semiconducting n$\mathrm{Si} / \mathrm{Au}$, bare $\mathrm{n}-\mathrm{Si}$, and metallic $\mathrm{p}^{*}$-Si/Au LAES. Fig. 3a shows CVs of $1 \mathrm{mM}$ FcMeOH using an n-Si/Au Schottky junction LAES. The samples show a slight gradual positive shift of the $E_{1 / 2}$ value over the 1000 cycles (from $-0.129 \mathrm{~V}$ to $-0.117 \mathrm{~V})$, but a minor decay in the current ( $20 \%$ decrease) and a small shift in peak separation (from $66 \mathrm{mV}$ to $75 \mathrm{mV}$ ). Switzer et al. observed a qualitatively similar trend when using similarly prepared electrodes and attributed the shift to the formation of $\mathrm{SiO}_{\mathrm{x}}$ species at the $\mathrm{Si}$ surface. ${ }^{31}$ It is especially likely that oxides would form on our samples, given that only $\approx 31 \%$ of the samples are protected by $\mathrm{Au}$. However, the minor changes in both peak currents and $\Delta E_{\mathrm{p}}$ suggest that the oxides are thin enough to not add significant resistance to the sensor and do not impact the junction energetics significantly. In fact, ultrathin oxides are often used to stabilize photoelectrodes for solar fuels applications $\mathrm{s}^{21,23,24}$ and have been shown to increase the stability of NP coated Si electrodes. ${ }^{53}$

We performed two control experiments to better understand the results in Fig. 3a. First, we tested to see if the presence of Au NPs impacts the stability. Fig. 3b shows CVs of a freshly etched n-Si electrode (without Au NPs) cycled 1000 times. There are dramatic shifts in the CV shape, peak currents, and $\Delta E_{\mathrm{p}}$ values that are consistent with oxide-passivation of the Si surface. ${ }^{31}$ Without Au NPs on the surface, HET between $\mathrm{Si}$ and $\mathrm{FcMeOH}$ is sluggish, and as the oxide grows HET rate dramatically decreases. This suggests 
that on the $\mathrm{n}-\mathrm{Si} / \mathrm{Au}$ samples, even when the oxide forms, electrons are able to tunnel efficiently between the Au NPs and the Si surface. Second, we used highly-doped (metallic) p*-Si and electrodeposited Au to see how carrier generation/transport impacts the formation of the oxide (Fig. 3c). The p*Si-Au samples showed very little decrease in peak current, and almost no shift in $E_{1 / 2}$ or $\Delta E_{\mathrm{p}}$. This suggests that the subtle $(\sim 12 \mathrm{mV})$ shift in $E_{1 / 2}$ using the n-Si/Au sensors may be due to the formation of an oxide between the $\mathrm{Au}$ NPs and n-Si. More detailed studies on this are currently underway and will be reported in due course.
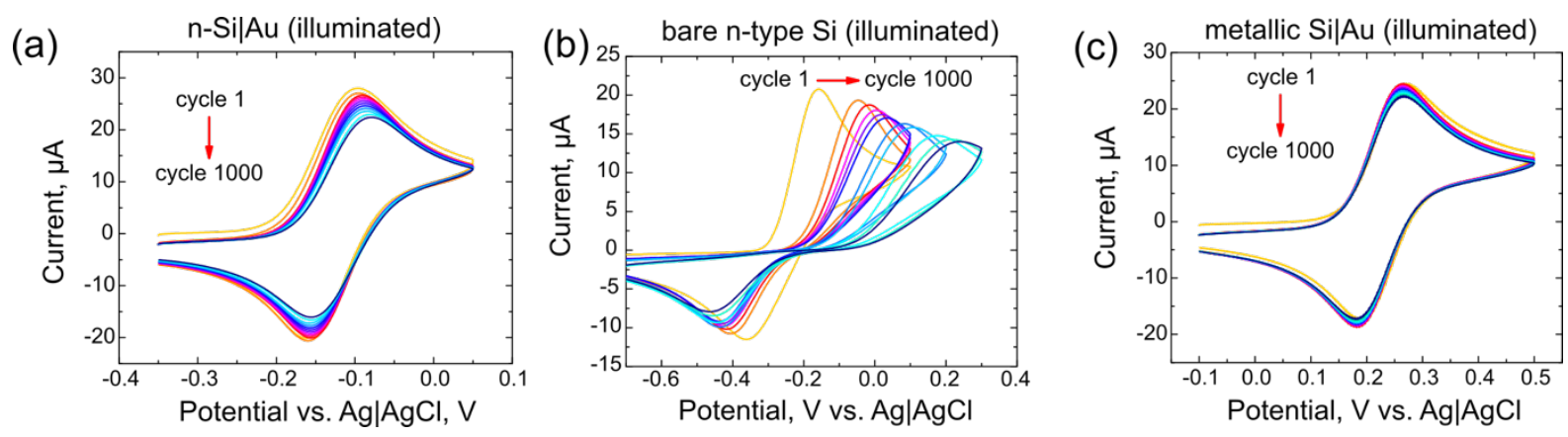

Figure 3: Sensors fabricated using n-Si and Au NPs are stable for at least 1000 cycles. (a) Consecutive CVs of $1 \mathrm{mM} \mathrm{FcMeOH}, 0.1 \mathrm{M} \mathrm{KCl}$ using n-type Si/Au electrode under illumination. (b) Consecutive CVs of $1 \mathrm{mM} \mathrm{FcMeOH}, 0.1 \mathrm{M} \mathrm{KCl}$ using a bare n-type Si electrode under full illumination. (c) Consecutive CVs of $1 \mathrm{mM} \mathrm{FcMeOH}, 0.1 \mathrm{M} \mathrm{KCl}$ using a highly doped $\mathrm{Si} / \mathrm{Au}$ photoelectrode under full illumination.

Scan rate $=0.1 \mathrm{~V} \mathrm{~s}^{-1}$, reference electrode $=\mathrm{Ag} / \mathrm{AgCl}$, counter electrode $=$ graphite rod.

Photoelectrochemical sensing of dopamine. After demonstrating that n-Si/Au Schottky junctions have excellent electrochemical behavior in $\mathrm{FcMeOH}$ and $\mathrm{Fe}(\mathrm{CN})_{6}{ }^{4-}$, we challenged them by using the more complex $2 \mathrm{e}^{-} / 2 \mathrm{H}^{+}$oxidation of dopamine in $\mathrm{pH} 8$ phosphate buffered saline (PBS). Dopamine has a redox potential of $\sim 0.2 \mathrm{~V}$ vs. $\mathrm{Ag} / \mathrm{AgCl}$ in vivo. ${ }^{54}$ Therefore, based on the $E_{\mathrm{fb}}$ measurements (see above), dopamine should be able to be studied using these n-Si/Au Schottky junctions. The blue trace in Fig. 4a shows the voltammetric response of a $2 \mathrm{~mm}$ diameter Au disk electrode towards $1 \mathrm{mM}$ dopamine in PBS. The black trace in Fig. 4a shows the response of the n-Si/Au sensor to dopamine in PBS in the dark and the red trace shows the sensor after illumination. The electrode was active only when illuminated and negligible current was passed when no illumination was used (Fig 4a, red and black traces, respectively). The large peak separation $\left(\Delta E_{\mathrm{p}}=98 \mathrm{mV}\right)$ observed for the semiconducting samples indicates sluggish HET kinetics but is consistent with what we observed using a traditional Au disk electrode. Control samples prepared using 
freshly-etched $\mathrm{n}-\mathrm{Si}$ without $\mathrm{Au}$ NPs showed a very broad oxidation peak for dopamine which was completely irreversible (Fig. S10). We tested the ability of the sensor to perform quantitative analysis over the concentration range from $15-500 \mu \mathrm{M}$. The electrode was responsive to changes in dopamine concentration over the range from $15-500 \mu \mathrm{M}$ with very good linearity (Fig. $4 \mathrm{c} ; R^{2}=0.9860$ ). The sensitivity of the sensor was $0.073 \pm 0.004 \mu \mathrm{A} \mu \mathrm{M}^{-1}$ and the LOD $\left(=3 \sigma_{\text {blank }} / \mathrm{m}\right)$ was $8.4 \mu \mathrm{M}$. There is considerable scope for improving the detection limit by using a pulsed voltammetric technique (e.g., square wave voltammetry $)^{55}$ or incorporating the sensors into a microfluidic flow cell. ${ }^{56}$ This range of concentrations is physiologically relevant under certain constraints. Dopamine concentrations change rapidly after exocytosis, ${ }^{57}$ but this concentration range would be able to detect dopamine at physiological concentrations $\sim 100 \mathrm{~ms}$ after exocytosis assuming diffusional mixing. ${ }^{58}$

(a)

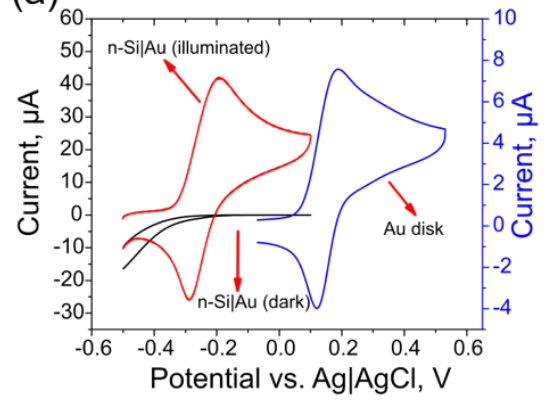

(b)

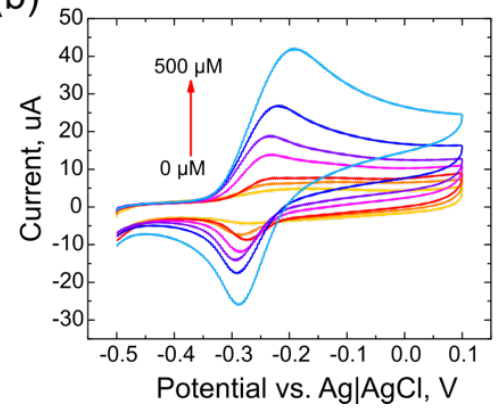

(c)

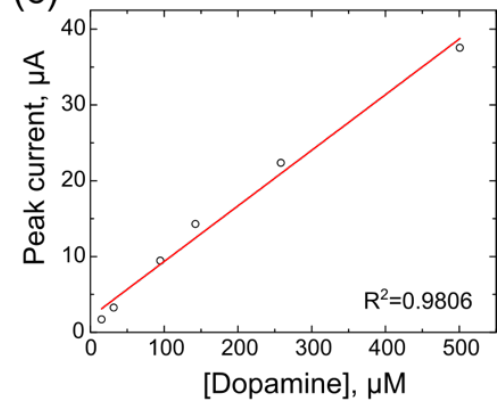

Figure 4: Sensors based on $\mathrm{n}-\mathrm{Si}$ and electrodeposited $\mathrm{Au}$ are light-activated and quantitative for dopamine. (a) CVs of $0.5 \mathrm{mM}$ dopamine in PBS buffer using Au disk electrode in the dark (blue trace), and semiconducting n-type $\mathrm{Si} / \mathrm{Au}$ photoelectrodes in the dark (black trace) and fully illuminated (red trace). (b) CVs of increasing dopamine concentrations using an n-type $\mathrm{Si} / \mathrm{Au}$ photoelectrode under full illumination. (c) Calibration curve for dopamine solutions using the $\mathrm{n}-\mathrm{Si} / \mathrm{Au}$ photoelectrode under full illumination. Scan rate $=0.25 \mathrm{~V} \mathrm{~s}^{-1}$, reference electrode $=\mathrm{Ag} / \mathrm{AgCl}$, counter electrode $=$ graphite rod.

Locally illuminated electrochemistry to circumvent sensor failure. Using LAES has several interesting applications: increasing the density of measurements using a single electrode ${ }^{10}$ imaging of semiconductor surfaces, ${ }^{11,12}$ patterning surfaces, ${ }^{14,15,59}$ and single cell studies. ${ }^{11,37}$ Here, we demonstrate a new application of local illumination whereby we eliminate total sensor failure during electrochemicallyinduced biofouling, which is a common issue with electrochemical sensing of biologically relevant compounds. ${ }^{60,61}$ Dopamine is known to foul electrodes by forming polydopamine, an insulating polymer 
that adsorbs onto the electrode surface. ${ }^{42,43}$ Fig 5a shows the repeated CVs obtained consecutively in $1 \mathrm{mM}$ dopamine in PBS at a scan rate of $0.1 \mathrm{~V} \mathrm{~s}^{-1}$. In dopamine, the electrode degraded rapidly, with $\sim 25 \%$ of the current decreasing between the first and second cycles, with complete fouling occurring after 100 cycles. The fouled surface completely blocks electron transfer, rendering the sensor useless. To confirm that the electrode surface was fouled, we measured CVs of FcMeOH before and after dopamine cycling (Fig. S11). Prior to dopamine cycling, the sensor behaves similar to Fig. 2a. After cycling, the CV is featureless and the entire sensing surface is not useable.

We are able to circumvent this problem using localized illumination. Fig $5 \mathrm{~b}$ shows a chopped light $i$ - $t$ curve in $1 \mathrm{mM}$ dopamine at $0.1 \mathrm{~V}$ vs. $\mathrm{Ag} / \mathrm{AgCl}$. The relatively high concentration of dopamine was chosen to exacerbate dopamine fouling on the surface and the potential was chosen to give a diffusionlimited response towards dopamine. In the initial 10 -seconds of each $i-t$ trace there is initially no light on the sample. During this time, the $i-t$ trace is featureless, highlighting that the entire macroscopic electrode surface is "off" because the Schottky junction is in depletion. After 10 seconds, a focused light beam was applied to a small region of the sample $(\sim 500 \mu \mathrm{m}$ diameter $)$ using the setup shown in Fig. S10. Upon illumination, the diffusion-limited oxidation of dopamine takes place at the illuminated portions of the sensor. The 20 -second cycle was repeated 10 times consecutively at each location. As the cycle number increases, the current transient minimum decreases because polydopamine is forming at only the illuminated portions of the sensor (Fig. 5b) and blocks the interface for electron transfer. As seen in Fig. $5 \mathrm{a}$, when the entire surface was illuminated, the sensor is fouled completely. However, using local illumination we simply moved the light beam to a fresh location and repeated the experiment. At each fresh location we observed a similar trend, where the current of the first cycle rapidly decays during the 10 cycles (Fig. S12). This gives confidence that the temporary array can be used for repetitive measurements of fouling analytes. Fig. 5c shows the decrease in current normalized to the first scan as a function of scan number:

$$
i_{\text {rel }}=\frac{i_{n}}{i_{\text {initial }}} x 100 \%
$$


where $i_{\text {rel }}$ is the relative current, $i_{\mathrm{n}}$ is the current of a given scan, and $i_{\text {initial }}$ is the current of the first scan. The currents for each spot were normalized using the steady state limiting current for scan 1 because the initial currents varied by $\sim 20 \%$ (Fig. S12). The current decay is remarkably similar at each location, giving promise to this method of repeated analysis for compounds that foul electrode surfaces.
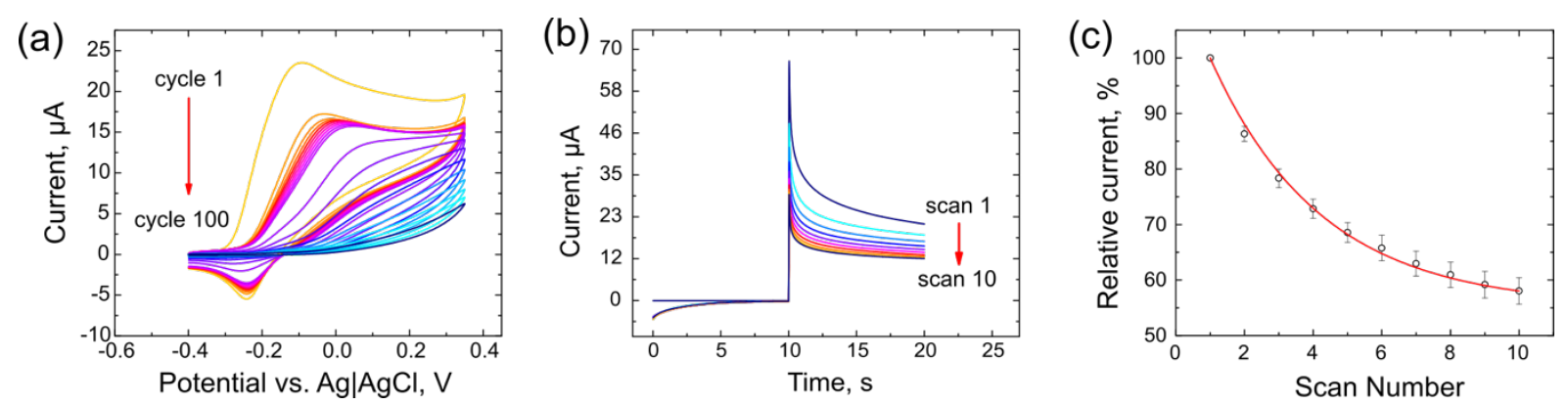

Figure 5: (a) Consecutive CVs of $1 \mathrm{mM}$ dopamine in PBS using n-Si/Au Schottky junction under illumination. Scan rate $=0.1 \mathrm{~V} \mathrm{~s}^{-1}$, reference electrode $=\mathrm{Ag} / \mathrm{AgCl}$, counter electrode $=$ graphite rod. (b) Chopped light local illumination $i$ - $t$ curve of $1 \mathrm{mM}$ dopamine in PBS at $0.1 \mathrm{~V}$. (c) Relative steady state current $\%$ vs. scan number for 7 different spots. Error bars represent $95 \%$ confidence interval for 6 degrees of freedom. For all measurements, the current was measured at $t=20$ seconds.

\section{CONCLUSIONS}

To date, the vast majority of LAES employ a chemically-modified Si surface that includes a redox molecule. In this contribution, we show that using semiconductor/metal (Schottky) junctions can be used as LAES and demonstrate their use for neurotransmitter sensing. This configuration is attractive because it allows for simple preparation of LAES and enables the direct measurement of freely-diffusing redox couples. We prepared the n-Si/Au Schottky junction LAES using by electrodepositing Au NPs on the n-Si surface, and characterized the LAES using scanning electron microscopy, electrochemical impedance spectroscopy, and cyclic voltammetry. Although the Au NP covered only $\sim 30 \%$ of the sensor surface, we observed fast HET kinetics for FcMeOH oxidation and long-term stability over $1000 \mathrm{CV}$ cycles. We also challenged the LAES to detect the neurotransmitter dopamine and found that the sensors were quantitative over the range from $15-500 \mu \mathrm{M}$ in buffer with a limit of detection of $8.4 \mu \mathrm{M}$, demonstrating that these sensors have potential for quantifying freely-diffusing neurotransmitters. Additionally, we used local 
illumination to generate a virtual array of electrochemical sensors for dopamine. We used the virtual array to eliminate total sensor failure during electrochemically-induced biofouling, which is a common issue with electrochemical sensing of biologically relevant compounds.

\section{ACKNOWLEDGEMENTS}

ITR acknowledges support from Montclair State University and Dominican Republic's Ministry of Higher Education, Science and Technology (MESCyT). We also acknowledge Montclair State University for startup funding, and Prof. Julie Macpherson for helpful suggestions and careful reading of the manuscript.

\section{References}

(1) Licht, S.; Myung, N.; Sun, Y. Anal. Chem. 1996, 68 (6), 954-959.

(2) Vogel, Y. B.; Gooding, J. J.; Ciampi, S. Chem. Soc. Rev. 2019, doi: 10.1039/c8cs00762d.

(3) Walter, M. G.; Warren, E. L.; McKone, J. R.; Boettcher, S. W.; Mi, Q.; Santori, E. A.; Lewis, N. S. Chem. Rev. 2010, 110, 6446-6473.

(4) Lewis, N. S. Inorg. Chem. 2005, 44 (20), 6900-6911.

(5) Lewis, N. S. Acc. Chem. Res. 1990, 23 (1), 176-183.

(6) Santangelo, P. G.; Miskelly, G. M.; Lewis, N. S. J. Phys. Chem. 1988, 92 (22), 6359-6367.

(7) Santangelo, P. G.; Miskelly, G. M.; Lewis, N. S. J. Phys. Chem. 1989, 6128-6136.

(8) Santangelo, P. G.; Lieberman, M.; Lewis, N. S. J. Phys. Chem. B 1998, 5647 (3), 4731-4738.

(9) Bard, A. J.; Faulkner, L. R. Electrochemical Methods: Fundamentals and Applications, Second Edi.; John Wiley \& Sons, Inc.: New York, 2001.

(10) Choudhury, M. H.; Ciampi, S.; Yang, Y.; Tavallaie, R.; Zhu, Y.; Zarei, L.; Gonçales, V. R.; Gooding, J. J. Chem. Sci. 2015, 6 (12), 6769-6776.

(11) Yang, Y.; Cuartero, M.; Gonåales, V. R.; Gooding, J. J.; Bakker, E. Angew. Chem. Int. Ed. 2018, $57,10.1002 /$ anie.201811268.

(12) Lian, J.; Yang, Y.; Wang, W.; Parker, S. G.; Gonçales, V. R.; Tilley, D.; Gooding, J. J. Chem. Commun. 2019, 123-126.

(13) Wu, F.; Zhou, B.; Wang, J.; Zhong, M.; Das, A.; Watkinson, M.; Hing, K.; Zhang, D.-W.; Krause, S. Anal. Chem. 2019, 91, 5896-5903.

(14) Chung, T. D.; Lim, S. Y.; Kim, Y.-R.; Ha, K.; Lee, J.-K.; Lee, J. G.; Jang, W.; Lee, J.-Y.; Bae, J. H. 
Energy Environ. Sci. 2015, 8, 3654-3662.

(15) Lim, S. Y.; Han, D.; Kim, Y.; Chung, T. D. ACS Appl. Mater. Interfaces 2017, 9, 23698-23706.

(16) Vogel, Y. B.; Zhang, L.; Darwish, N.; Gonçales, V. R.; Le Brun, A.; Gooding, J. J.; Molina, A.; Wallace, G. G.; Coote, M. L.; Gonzalez, J.; Ciampi, S. Nat. Commun. 2017, 8 (1).

(17) Pourbaix, M. Atlas of Electrochemical Equilibria in Aqueous Solutions, First.; Pergamon Press: New York, 1966.

(18) Bocarsly, A. B.; Bookbinder, D. C.; Dominey, R. N.; Lewis, N. S.; Wrighton, M. S. J. Am. Chem. Soc. 1980, 102 (11), 3683-3688.

(19) Heben, M. J.; Kumar, A.; Zheng, C.; Lewis, N. S. Nature 1989, 340, 621-623.

(20) Kumar, A.; Lewis, N. S. J. Phys. Chem. 1991, 95 (18), 7021-7028.

(21) Esposito, D. V; Levin, I.; Moffat, T. P.; Talin, A. A. Nat. Mater. 2013, 12 (6), 562-568.

(22) Ji, L.; McDaniel, M. D.; Wang, S.; Posadas, A. B.; Li, X.; Huang, H.; Lee, J. C.; Demkov, A. a; Bard, A. J.; Ekerdt, J. G.; Yu, E. T. Nat. Nanotechnol. 2015, 10, 84-90.

(23) Scheuermann, A. G.; Lawrence, J. P.; Kemp, K. W.; Ito, T.; Walsh, A.; Chidsey, C. E. D.; Hurley, P. K.; McIntyre, P. C. Nat. Mater. 2015, No. October, 1-8.

(24) Scheuermann, A. G.; McIntyre, P. C. J. Phys. Chem. Lett. 2016, acs.jpclett.6b00631.

(25) Nielander, A. C.; Bierman, M. J.; Petrone, N.; Nicholas, C.; Ardo, S. A.; Yang, F.; Hone, J.; Lewis, N. S. J. Am. Chem. Soc. 2013, 30 (111), 1-4.

(26) Lee, S. C.; Some, S.; Kim, S. W.; Kim, S. J.; Seo, J.; Lee, J.; Lee, T.; Ahn, J.; Choi, H.; Jun, S. C. Nat. Publ. Gr. 2014, 1-9.

(27) Marrani, A. G.; Zanoni, R.; Schrebler, R.; Dalchiele, E. A. J. Phys. Chem. C 2017.

(28) Ciampi, S.; Eggers, P. K.; Saux, G. Le; James, M.; Harper, J. B.; Gooding, J. J. Langmuir 2009, No. 100, 2530-2539.

(29) Kenney, M. J.; Gong, M.; Li, Y.; Wu, J. Z.; Feng, J.; Lanza, M.; Dai, H. Science 2013, 342, 836840.

(30) Prod'Homme, P.; Maroun, F.; Cortès, R.; Allongue, P. Appl. Phys. Lett. 2008, 93 (17), 21-24.

(31) Chen, Q.; Switzer, J. A. ACS Appl. Mater. Interfaces 2018, 10 (25), 21365-21371.

(32) Kashi, M. B.; Silva, S. M.; Yang, Y.; Gonçales, V. R.; Parker, S. G.; Barfidokht, A.; Ciampi, S.; Gooding, J. J. Electrochim. Acta 2017, 251, 250-255.

(33) Yang, Y.; Ciampi, S.; Choudhury, M. H.; Gooding, J. J. J. Phys. Chem. C 2016, acs.jpcc.5b12097.

(34) Ahmad, S.; Ciampi, S.; Parker, S.; Goncales, V. R.; Gooding, J. J. ChemElectroChem 2018, doi: 10.1002/celc. 201800717.

(35) Choudhury, M. H.; Ciampi, S.; Lu, X.; Kashi, M. B.; Zhao, C.; Gooding, J. J. Electrochim. Acta 2017, 242, 240-246. 
(36) Yang, Y.; Ciampi, S.; Gooding, J. J. Langmuir 2017, 33, 2497-2503.

(37) Parker, S. G.; Yang, Y.; Ciampi, S.; Gupta, B.; Kimpton, K.; Mansfeld, F.; Kavallaris, M.; Gaus, K.; Gooding, J. J. Nat. Commun. 2018, 9, 2288.

(38) Kashi, M. B.; Wu, Y.; Gonçales, V. R.; Choudhury, M. H.; Ciampi, S.; Gooding, J. J. Electrochem. commun. 2016, 70, 28-32.

(39) Seo, D.; Lim, S. Y.; Lee, J.; Yun, J.; Chung, T. D. ACS Appl. Mater. Interfaces 2018, 10, 3366233668 .

(40) Zhao, S.; Völkner, J.; Riedel, M.; Witte, G.; Yue, Z.; Lisdat, F.; Parak, W. J. ACS Appl. Mater. Interfaces 2019, 11, 21830-21839.

(41) Yue, Z.; Lisdat, F.; Parak, W. J.; Hickey, S. G.; Tu, L.; Sabir, N.; Dorfs, D.; Bigall, N. C. ACS Appl. Mater. Interfaces 2013, 5, 2800-2814.

(42) Peltola, E.; Sainio, S.; Holt, K. B.; Paloma, T.; Laurila, T. Anal. Chem. 2018, 90, 1408-1416.

(43) Patel, A. N.; Tan, S.-Y.; Miller, T. S.; Macpherson, J. V; Unwin, P. R. Anal. Chem. 2013, 85, 1175511764.

(44) Gelderman, K.; Lee, L.; Donne, S. W. J. Chem. Educ. 2007, 84 (4), 685.

(45) Acharya, S.; Lancaster, M.; Maldonado, S. Anal. Chem. 2018.

(46) McCreery, R. L. Chem. Rev. 2008, 108 (7), 2646-2687.

(47) Ammann, D.; Pretsch, E.; Simon, W.; Lindner, E.; Bezegh, A.; Pungor, E. Anal. Chim. Acta 1985, $171,119-129$.

(48) Park, J. H.; Thorgaard, S. N.; Zhang, B.; Bard, A. J. J. Am. Chem. Soc. 2013, 135, 5258-5261.

(49) Vogel, Y. B.; Molina, A.; Gonzalez, J.; Ciampi, S. Anal. Chem. 2019.

(50) Nicholson, R. S. Anal. Chem. 1965, 37, 1351-1355.

(51) Velicky, M.; Bradley, D. F.; Cooper, A. J.; Hill, E. W.; Kinloch, I. A.; Mishchenko, A.; Novoselov, K. S.; Patten, H. V; Toth, P. S.; Valota, A. T.; Worrall, S. D.; Dryfe, R. A. W. ACS Nano 2014, 8, 10089-10100.

(52) Lavagnini, I.; Antiochia, R.; Magno, F. Electroanalysis 2004, 16 (6), 505-506.

(53) Oh, K.; Meriadec, C.; Lassalle-Kaiser, B.; Dorcet, V.; Fabre, B.; Ababou-Girard, S.; Joanny, L.; Gouttefangeas, F.; Loget, G. Energy Environ. Sci. 2018, 0-11.

(54) Robinson, D. L.; Hermans, A.; Seipel, A. T.; Wightman, R. M. Chem. Rev. 2008, 108 (7), 25542584.

(55) Cobb, S. J.; Macpherson, J. V. Anal. Chem. 2019, doi: 10.1021/acs.analchem.9b01857.

(56) O’Neil, G. D.; Ahmed, S.; Halloran, K.; Janusz, J. N.; Rodríguez, A.; Terrero Rodríguez, I. M. Electrochem. commun. 2019, 99, 56-60.

(57) Cragg, S. J.; Rice, M. E. Trends Neurosci. 2004, 27 (5), 270-277. 
(58) Polo, E.; Kruss, S. Anal. Bioanal. Chem. 2016, 408 (11), 2727-2741.

(59) Vogel, Y. B.; Gonc, V. R.; Gooding, J. J.; Ciampi, S. J. Electrochem. Soc. 2018, 165, H3085H3092.

(60) Simcox, L. J.; Pereira, R. P. A.; Wellington, E. M. H.; Macpherson, J. V. ACS Appl. Mater. Interfaces 2019, 11, 25024-25033.

(61) Barfidokht, A.; Gooding, J. J. Electroanalysis 2014, 26, 1182- 1196. 